\title{
Accumulation of Hyaluronan (Hyaluronic Acid) in Myocardial Interstitial Tissue Parallels Development of Transplantation Edema in Heart Allografts in Rats
}

\author{
Roger Hällgren, Bengt Gerdin, Anders Tengblad, and Gunnar Tufveson \\ Departments of Internal Medicine, Surgery and Urology, University Hospital, and the Department of Biochemistry, \\ Pharmacia AB, Uppsala, Sweden
}

\begin{abstract}
By using biotin-labeled proteoglycan core protein, hyaluronan (hyaluronic acid; HA) was visualized in rat heart grafts at different times $(2,4$, and 6 d) after transplantation. In normal, nontransplanted hearts $H A$ was present in the adventitia of arteries and veins and in the myocardial interstitial tissue. An increased accumulation of $\mathrm{HA}$ was evident in the edematous interstitial tissue, infiltrated with lymphocytes, on day 4 after allogeneic transplantation, and was even more pronounced by day 6. No apparent increase in HA was seen in syngeneic grafts. Biochemical assay of $\mathrm{HA}$ in heart tissue demonstrated that the myocardial content of HA had increased $60 \%$ by day 2 after transplantation in allogeneic as well as syngeneic grafts, indicating that surgical trauma may induce some HA accumulation in heart grafts. The extractable amounts of HA declined during the following days in the syngeneic grafts, but increased progressively during the development of rejection in the allogeneic grafts, and increased on average three times by day 6 . The relative water content also increased progressively during rejection of allogeneic grafts and correlated with the $\mathrm{HA}$ accumulation. The interstitial accumulation of HA, a glycosaminoglycan with unique water-binding qualities, is presumably implicated in the development of interstitial edema during rejection of heart grafts. (J. Clin. Invest. 1990. 85:668-673.) hyaluronic acid • heart graft • allograft • rejection • edema
\end{abstract}

\section{Introduction}

Previous studies on the formation and remodeling of extracellular matrix in transplanted organs have mainly focused on the latter stages of rejection and the development of fibrosis. The early stage of the connective tissue response during rejection has until now been little studied. The early remodeling process of the matrix may be important not only for the later development of granulation tissue but also for the function of the graft. Accumulation of the connective tissue component hyaluronan (HA) ${ }^{1}$ (hyaluronic acid or hyaluronate by older nomenclature [1]) is an early event after an inflammatory injury (2). The

Address correspondence to Dr. Roger Hällgren, Department of Internal Medicine, Section of Rheumatology, University Hospital, S-751 85 Uppsala, Sweden.

Received for publication 24 April 1989 and in revised form 15 September 1989.

1. Abbreviations used in this paper: HA, hyaluronan; HABP, HA-binding region of the cartilage proteoglycan.

J. Clin. Invest.

(c) The American Society for Clinical Investigation, Inc.

0021-9738/90/03/0668/06 \$2.00

Volume 85, March 1990, 668-673 synthesis of HA in rejecting grafts has not previously been investigated, but a number of inflammatory mediators likely to be operative during rejection have been reported to enhance the HA synthesis by mesenchymal cells (3-5). HA is a linear polymer built up of the repeating disaccharide $\mathrm{N}$-acetylglucosamine-glucuronic acid and an important constituent of loose connective tissue $(6,7)$. The properties of HA are important for water homeostasis; it attracts water by osmotic forces and resists water flow $(7,8)$. Thus, excessive accumulation of HA in interstitial tissue might immobilize water and contribute to interstitial tissue edema $(9,10)$. Assuming that HA synthesis is enhanced during rejection, the water-binding properties of HA may be of utmost importance for the development of transplantation edema, and thereby a threat to graft function.

In this study we localized HA in heart grafts of rats by using a specific probe to HA. The accumulation of HA in the graft during different phases of rejection was quantified by a biochemical assay. The accumulation of HA in the graft tissue was correlated to the development of the transplantation edema.

\section{Methods}

Animals. Lewis and DA rats (originally derived from Møllegaard, Skensved, Denmark, and from Bantin \& Kingman, N. Humberside, UK, respectively) were bred in our own animal department. The male rats used for the experiments weighed $150-200 \mathrm{~g}$.

Transplantation. Donor rats were anaesthetized with intraperitoneally administered thiobutabarbital (Byk, Konstanz, FRG), $120 \mathrm{mg} / \mathrm{kg}$ body wt. Recipients were anaesthetized with an intraperitoneal injection of chloral hydrate solution, $3.5 \mathrm{mg} / \mathrm{kg}$ body wt. The donor hearts were flushed through the caval vein with 1-2 $\mathrm{ml}$ of an ice-cold histidine-buffered perfusion solution with ionic composition corresponding to extracellular fluid (11). The aorta was then flushed with another $2 \mathrm{ml}$ of the perfusion fluid and the heart was removed after ligation of the caval and pulmonary veins. A nonsuture anastomose technique originally described by Heron (12) and later modified (13) was used for organ grafting. The donor heart was heterotopically transplanted to the neck vessels of the recipient: the aortic root was anastomosed to the right common carotid artery and the pulmonary artery to the right jugular vein of the recipient. The total duration of cold ischemia for the heart was 5-10 min.

Syngeneic graft transplantation was performed between Lewis rats and allogeneic graft transplantation with DA rats as donors and Lewis rats as recipients. 2,4 , and $6 \mathrm{~d}$ after transplantation, the anaesthetized rats were exsanguinated. The heart graft and the animal's own heart were immediately taken out and used for either histopathological examination or tissue analysis of total graft HA and water content.

Heart tissue preparation, extraction of tissue $\mathrm{HA}$, and calculation of water content. All preparations were made immediately after death. Hearts and cardiac grafts used for histopathology were fixed in $1 \%$ cetylpyridinium chloride buffered $4 \%$ formalin, $\mathrm{pH} 7.3$, and stored at room temperature until paraffin-embedded and sectioned. Hearts and grafts for tissue analysis of HA and water were weighed immediately on 
filter paper at room temperature (wet weight) and later after lyophilization at $-80^{\circ} \mathrm{C}$ for $4 \mathrm{~d}$ (dry weight). The relative water content of heart was calculated according to the formula $\frac{\text { w.w. }- \text { d.w. }}{\text { w.w. }} \times 100$, where w.w. is wet weight and d.w. is dry weight. The HA was extracted from the pulverized dried cardiac tissue with $0.5 \mathrm{M} \mathrm{NaCl} .20 \mathrm{mg}$ of the heart material was extracted with $2 \mathrm{ml}$ of the buffer for $16 \mathrm{~h}$ with constant shaking at $4^{\circ} \mathrm{C}$. The samples were then centrifuged for $15 \mathrm{~min}$ at 2,000 $g$. The supernatants were recovered and the HA concentrations analyzed in duplicate with a radiometric assay (Pharmacia Diagnostics, Uppsala, Sweden) according to the principles previously outlined (14). Briefly, $100 \mu \mathrm{l}$ sample or standard was mixed with $200 \mu \mathrm{l}{ }^{125} \mathrm{I}$-labeled HA-binding protein (HABP; with specific affinity for HA and isolated from bovine nasal cartilage) and incubated for $60 \mathrm{~min}$ at $4-7^{\circ} \mathrm{C} .100 \mu \mathrm{l}$ HA-Sepharose at a concentration of $1 \mathrm{mg} / \mathrm{ml}$ was then added and the tubes were incubated for an additional $45 \mathrm{~min}$ at the same temperature. $2 \mathrm{ml}$ of washing solution was added and the HA-Sepharose recovered after centrifugation at $2,000 \mathrm{~g}$ for $10 \mathrm{~min}$. Bound radioactivity in the pellet was measured in a gamma counter. Known amounts of HA were used to construct a standard curve. The radioactivity was plotted as a function of HA concentrations in the samples. The variability of the assay was $<10 \%$.

Localization of HA in heart tissue. An avidin-enzyme, biotin-protein system was used for the detection of HA in tissue. The method is based on the very specific interaction between $\mathrm{HA}$ and the protein core of the cartilage proteoglycan (15). The technique contains three major steps: $(a)$ the specific binding of biotin-labeled protein to HA in the fixed tissue; $(b)$ the binding of an avidin-enzyme complex to the biotin; and $(c)$ visualization of bound enzyme with a substrate.

The HA-binding region of the cartilage proteoglycan (HABP) was prepared by affinity chromatography on HA-Sepharose as described previously (16). The purified protein was then linked to biotin according to the principles outlined by Ripellino and associates (17). To protect the HA-binding site on the HABP HA used during the biotinylation was then removed by affinity chromatography on HA-Sepharose. HABP-biotin was stored at $-20^{\circ} \mathrm{C}$ at a concentration of $150-160$ $\mu \mathrm{g}$ protein $/ \mathrm{ml}$ until used.

Before staining for HA, the heart tissues were dehydrated in ethanol, cleared in xylene, and embedded in paraffin. Serial sections, $5 \mu \mathrm{m}$ thick, were cut at five levels and put on gelatin-coated slides, deparaffinized, and brought through a graded ethanol series to water. The staining for $\mathrm{HA}$ was performed according to a modification of the technique described by Ripellino and associates (17). All steps were performed at room temperature unless otherwise stated. The sections were first incubated with $3 \% \mathrm{H}_{2} \mathrm{O}_{2}$ for 5 min to eliminate endogenous peroxidase activity and then with BSA (fraction V, A4503; Sigma Chemical Co., St. Louis, MO), $10 \mathrm{mg} / \mathrm{ml}$, to block nonspecific binding sites. After two 10-min washes with PBS, pH 7.3, the sections were incubated overnight at $4^{\circ} \mathrm{C}$ with HABP-biotin $(50-60 \mu \mathrm{g} / \mathrm{ml})$. After two 10-min washes in PBS, the sections were incubated with ABC Vectastain Reagent (Vector Laboratories, Inc., Burlingame, CA). After three 10-min washes in PBS the slides were incubated for $5 \mathrm{~min}$ in ethyl carbozole-DMSO (10 mg 3-amino-9-ethylcarbazole; Karl Roth, Karlsruhe, FRG) in $6 \mathrm{ml}$ DMSO (Merck, Darmstadt, FRG) dissolved in a mixture of $40 \mathrm{ml}$ acetate buffer, $\mathrm{pH} 5.0$, and $5 \mu \mathrm{l} \mathrm{H}_{2} \mathrm{O}_{2}$. The sections were mounted under glass coverslips in Kaiser's glycerin-gelatin. The sections were examined by light microscopy by one observer without knowledge of the experimental conditions of the individual animals. The specificity of the reaction was checked with Streptomyces hyaluronidase (Seikagaku Fine Biochemicals, Tokyo, Japan). Control sections were incubated for $4 \mathrm{~h}$ in a humidified chamber at $37^{\circ} \mathrm{C}$ with $500 \mathrm{U} / \mathrm{ml}$ of Streptomyces hyaluronidase in $100 \mathrm{mM}$ sodium acetate buffer, $\mathrm{pH} 5.8$, in the presence of protease inhibitors (1.8 mM EDTA; Merck, Darmstadt, FRG), $1.8 \mu \mathrm{g} / \mathrm{ml}$ soya bean trypsin inhibitor (Worthington Biochemical Corp., Freehold, NJ), $2 \mathrm{mM}$ iodoacetic acid (Sigma Chemical Co.), $0.18 \mathrm{mM} \epsilon$-amino-n-caproic acid (Sigma Chemical Co.), $9 \mathrm{mM}$ bensamidine (Sigma Chemical Co.), and 1.8 $\mu \mathrm{g} / \mathrm{ml}$ pepstatin A (Sigma Chemical Co.).
For histopathologic investigations, sections of heart tissue were also stained with hematoxylin-eosin and with toluidine blue. Statistical analyses were performed by $t$ test on groups and paired values.

\section{Results}

Histopathological features and localization of $\mathrm{HA}$ in the heart tissue. In the normal heart tissue, positive staining for HA was observed in the adventitia of arteries and veins and the connective tissue of the perimysium (Fig. $1 \mathrm{~A}$ ). Positive staining for HA was also seen along the epi- and endocardium. A faint thin staining for HA was seen in the endomysium, giving the impression that individual muscle fibers were surrounded by a narrow lining of HA (Fig. $1 B$ ). The original heart of the animals that obtained allogeneic or syngeneic heart grafts had a similar staining pattern for HA on days 2-6 after transplantation.

$2 \mathrm{~d}$ after allografting the donor hearts $(n=4)$ exhibited an increased number of cells, mostly lymphocytes, in the interstitial space but also diffusely between the muscle fibers. Investigations on days $4(n=4)$ and $6(n=6)$ revealed that the cell infiltration increased progressively in the allogeneic grafts (Fig. $2 \mathrm{~B}$ ). The number of mast cells identified by toluidine blue decreased with time in the allogeneic graft. While the recipient's own heart contained 120-200 mast cells per section, the average mast cell number in the graft was $\sim 25$ on day 2 . The mast cells were virtually absent on day 6 . An increased distance between the muscle fibers in the graft was apparent on day 4. This finding was interpreted as an interstitial edema and was more pronounced on day 6. During the development of rejection, a uniform change of the staining pattern for $\mathrm{HA}$ was observed: from day 2 to day 6 a progressively larger area of each section stained for HA (Fig. $2 \mathrm{~B}$ ). The accumulation of HA was localized to the swollen endomysium which showed a homogenous positive staining for HA (Fig. 2, $C$ and $D$ ). The syngeneic grafts showed a slight increase in round cell infiltration on days 2-6. In the interstitial space HA staining was normal or only slightly increased.

$H A$ content in the heart tissue. The content of $\mathrm{HA}$ in the hearts of healthy control rats $(n=10)$ was on average $306 \pm 10$ (SEM) $\mu \mathrm{g} / \mathrm{g}$ dry weight as determined by extracting the freezedried and homogenized heart tissue with $0.5 \mathrm{M} \mathrm{NaCl}$.

Compared with the nontransplanted heart of the control rats, the HA content of the syngeneic cardiac graft increased by day 2 and was on average $527 \pm 30 \mu \mathrm{g} / \mathrm{g}$ d.w. $(P<0.001)$. By days 4 and 6 the HA content of the transplanted heart tended to decrease (Table I). In the allogeneic grafts the HA content was on average $512 \pm 37 \mu \mathrm{g} / \mathrm{g}$ d.w. on day $2(P<0.001)$. The HA content increased progressively $(P<0.01)$ on days 4 and 6 (Table I). By day 6 the average HA content of the allogenic graft was on average three times higher than in the healthy heart. The transplantation had no influence on the HA content of the animal's own heart (Table I).

Water content of the heart tissue. The relative water content of the healthy control rat heart was on average $76.4 \pm 0.2 \%$ (SEM) $(n=10)$. Compared with the heart of the controls, the relative water content was increased on day 2 to $79.9 \pm 0.4 \%$ in syngeneic grafts $(P<0.001)$ and to a similar extent in allogeneic grafts (Table I). In the syngeneic grafts the relative water content remained at the same level between days 4 and 6 , while in the allogeneic grafts the water content of the transplant increased progressively $(P<0.01)$ and on day 6 was close 

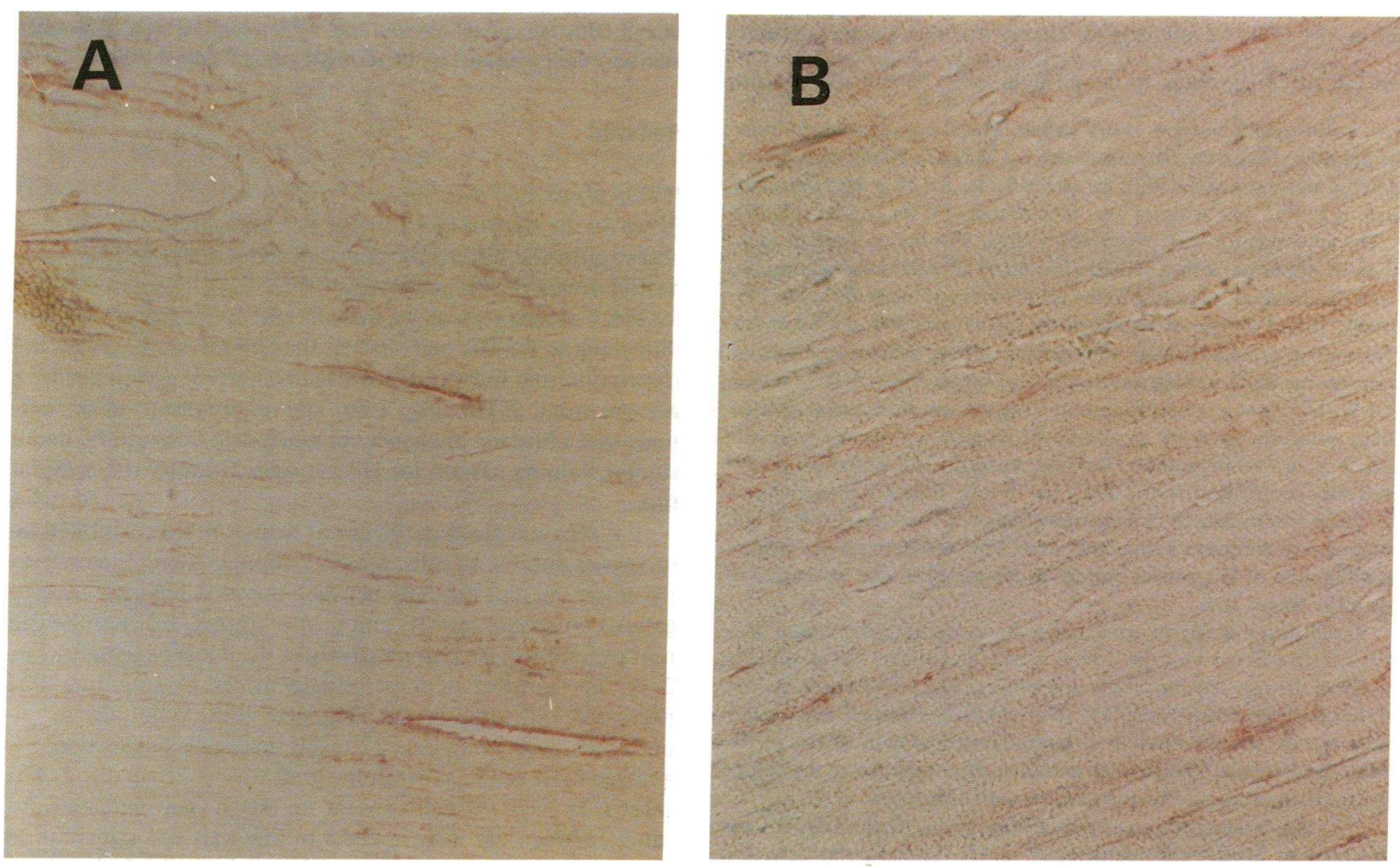

Figure 1. A, Cetylpyridinium chloride-formalin-fixed, paraffin-embedded rat heart tissue section with an artery at the top right. HA (brown color) is located in the adventitia of the artery and in the connective tissue of the perimysium. HA was detected by an indirect avidin-biotinperoxidase technique (see Methods). Original magnification $\times 100$. B. Tissue section of normal rat heart at higher magnification illustrates a positive, but discrete, HA staining of the endomysium. Original magnification $\times 400$.

to $83 \%$ (Table I). The water content of the nontransplanted heart was not influenced by the transplantation or the rejection of the transplant (Table I). There was a significant correlation between relative water and the HA contents of the allogeneic grafts $(r=0.62, P<0.05)$.

Using the values for the relative water content in control rat hearts (mean value $76.4 \%$ ) and in cardiac grafts on days 2-6 after allogeneic transplantation we calculated the increase in the total heart water after transplantation from the formula: w.w. of cardiac graft $\times 10^{-2}$ (cardiac graft water, \% - normal heart water, \%). The increase in the total HA content of the cardiac graft was also estimated: d.w. of cardiac graft $\times$ [HA in cardiac graft ( $\mu \mathrm{g} / \mathrm{g}$ d.w.) - HA in normal heart ( $\mu \mathrm{g} / \mathrm{g}$ d.w.)]. The increase in the amounts of total water and HA in cardiac grafts during the observation period was on average $50 \mathrm{mg}$ and $84 \mu \mathrm{g}$, respectively. This corresponds to a HA concentration of $1.6 \mathrm{mg} / \mathrm{ml}$ increased water volume.

\section{Discussion}

By using biotin-labeled proteoglycan core protein and an avidin-enzyme system (15), we have visualized HA in the healthy rat heart and followed the accumulation of HA in myocardial tissue during rejection of rat cardiac transplants. The presence of most of the HA in the healthy heart in the perivascular tissue and in the peri- and endomysium reflects the established role of $\mathrm{HA}$ in the stabilization of the tissue matrix. In the cardiac grafts undergoing rejection a progressive accumulation of HA in the edematous interstitium was apparent during the 6 $\mathrm{d}$ after transplantation. This HA could be removed by specific enzyme digestion. The possibility that the accessibility of the probe to HA is influenced by an extracellular matrix remodeling in transplanted heart injured by invading inflammatory cells cannot be fully excluded. However, the microscopic findings of a progressive HA accumulation during rejection were confirmed by direct biochemical assay of graft tissue HA. This recovery of extractable HA from the allogeneic graft had increased on average three times on day 6 posttransplant.

The major mechanism of HA clearance from the heart tissue is presumably via lymph drainage to the general circulation and uptake by the liver (18). The appearance of HA in the myocardial interstitial tissue after heart transplantation may therefore be partly due to surgical damage to the lymph vessels and impaired elimination of HA. In fact, the extractable myocardial HA had increased by $60 \%$ on the second postoperative day after both syngeneic and allogeneic heart transplantation. However, whereas the HA accumulation observed during - rejection of the allogeneic grafts increased progressively, the HA content of the syngeneic grafts leveled off and tended to decrease after the initial increase on day 2 after transplantation. It is therefore likely that the progressive HA accumulation during heart rejection is due to an enhanced HA synthesis in the interstitial tissue.

The cellular source of the myocardial HA during rejection has not been identified in this study. It is conceivable that fibroblasts or other mesenchymal cells present in the intersti- 

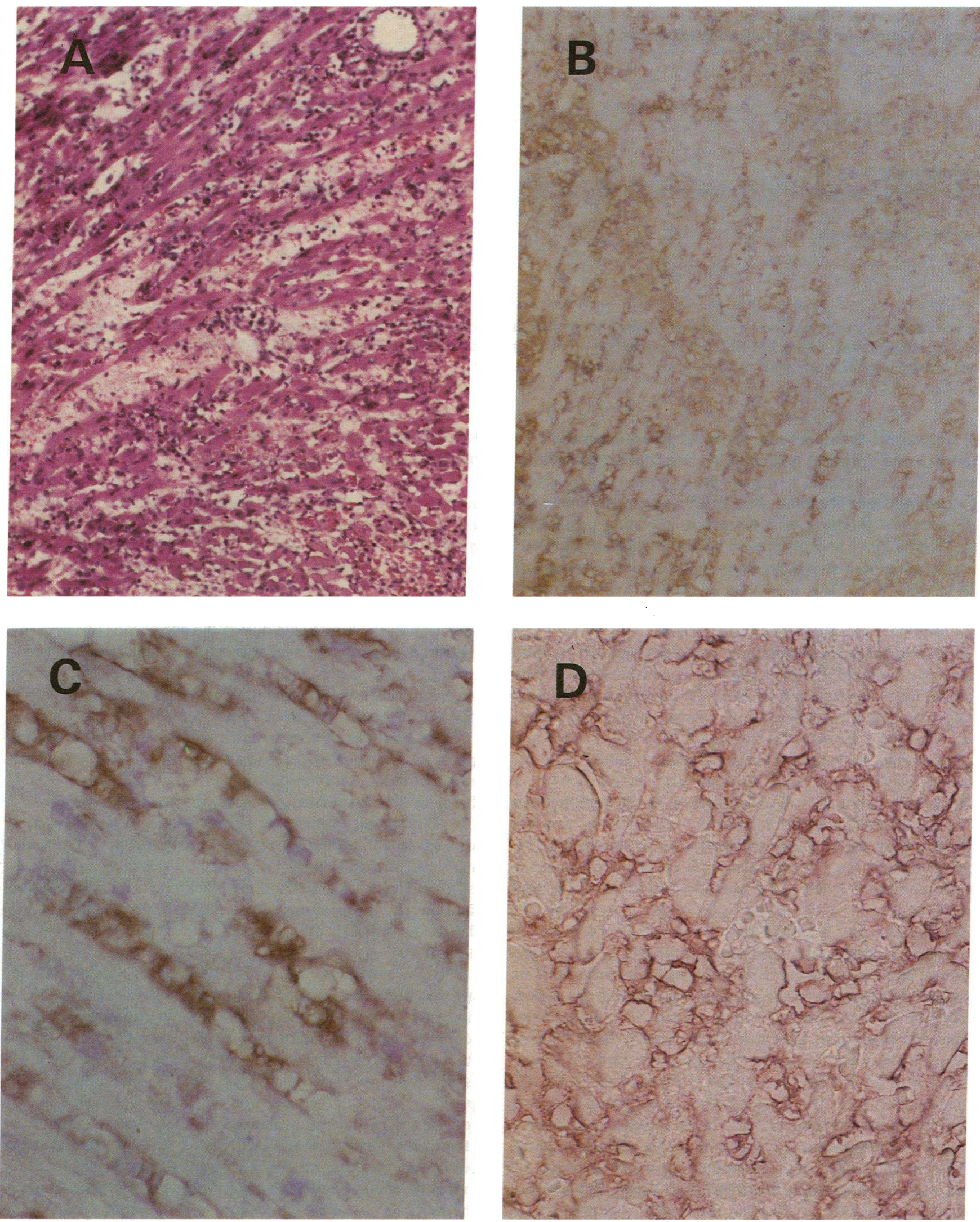

Figure 2. A, Tissue sections of cardiac graft $6 \mathrm{~d}$ after allogeneic transplantation. A pronounced cell infiltration is seen in the widened interstitial space. Hematoxylin-eosin, original magnification $\times 100$. B. Accumulation of HA is seen in the cell-rich widened interstitium. Original magnification $\times 100$. $C$ and $D$, At higher magnification (original magnification $\times 400$ ) the accumulation of HA was demonstrable in the endomysium connective tissue and is illustrated by longitudinal $(C$, counterstained with hematoxylin-eosin) and transverse sections $(D)$. 
Table I. Extracted HA Amounts and Relative Water Contents (Means \pm SEM) of Allogeneic and Syngeneic Heart Grafts at Various Times after Heart Transplantation in Rats

\begin{tabular}{|c|c|c|c|c|c|c|}
\hline & \multirow[b]{2}{*}{ Days posttransplantation } & \multirow[b]{2}{*}{$n$} & \multicolumn{2}{|c|}{ HA } & \multicolumn{2}{|c|}{ Water } \\
\hline & & & Heart graft & Own heart & Heart graft & Own heart \\
\hline & & & \multicolumn{2}{|c|}{$\mu g / g d . w}$. & \multicolumn{2}{|c|}{$\%$} \\
\hline \multirow[t]{3}{*}{ Allogeneic transplantation } & 2 & 4 & $512 \pm 37^{*}$ & $284 \pm 7$ & $79.5 \pm 0.6^{\ddagger}$ & $76.8 \pm 0.4$ \\
\hline & 4 & 5 & $715 \pm 12^{*}$ & $336 \pm 20$ & $80.6 \pm 1.1^{*}$ & $76.3 \pm 0.3$ \\
\hline & 6 & 4 & $930 \pm 13^{\ddagger}$ & $291 \pm 6$ & $82.9 \pm 0.7^{\ddagger}$ & $76.2 \pm 0.3$ \\
\hline \multirow[t]{3}{*}{ Syngeneic transplantation } & 2 & 3 & $527 \pm 29^{*}$ & $309 \pm 14$ & $79.9 \pm 0.4^{*}$ & $77.1 \pm 0.4$ \\
\hline & 4 & 3 & $438 \pm 14^{*}$ & $327 \pm 9$ & $80.5 \pm 0.3^{*}$ & $77.1 \pm 0.3$ \\
\hline & 6 & 3 & $465 \pm 42$ & $309 \pm 12$ & $79.6 \pm 0.3^{*}$ & $77.0 \pm 0.3$ \\
\hline
\end{tabular}

The contents of HA and water in the recipients' original nontransplanted hearts are also given. The extraction of HA was performed from freeze-dried heart tissue with $0.5 \mathrm{M} \mathrm{NaCl}$. ${ }^{*} P<0.05 ;^{\ddagger} P<0.01$. Statistical differences between the $\mathrm{HA}$ and water contents of the heart grafts and the original hearts were tested using the paired $t$ test.

tial myocardial tissue become activated to an enhanced HA production by immune mediators released during the cell invasion of the transplant. Lymphokines and macrophage products can influence fibroblast activity $(19,20)$, and a number of inflammatory products with fibroblast-activating properties, e.g., interleukin 1 and platelet-derived and epidermal growth factors, have been shown to stimulate fibroblast synthesis of HA in vitro $(3,5)$. Thus, several factors related to immunological and/or inflammatory responses of the heart graft rejection may stimulate HA synthesis in the heart.

HA has unique water-binding properties and can become extremely hydrated. Previous physical/chemical studies of HA in vitro have also shown that when the concentration of high molecular HA is $>0.2 \mathrm{mg} / \mathrm{ml}$, the molecules become entangled, forming a network that occupies the solvent space and excludes large molecules. This phenomenon, called steric exclusion, may influence water transport and osmotic activity in the intercellular matrix (8). The present study demonstrates that the water content of recipient's original heart was not influenced by the heart transplantation or by the allograft rejection. The increase in the water in the cardiac grafts seems to be the combined result of the operation trauma and the graft rejection. Thus, by the second posttransplantation day the water content had increased by $<3 \%$ in syngeneic as well as allogeneic cardiac grafts. During the following $4 \mathrm{~d}$ the water content remained constant in the syngeneic grafts, but increased progressively in the allogeneic grafts. On day 6 postoperation the water content was on average $5.7 \%$ higher in the allogeneic heart graft than that in the healthy heart. The increase in the water content of the syngeneic grafts was associated with an increase in the HA content of the graft. The increased HA content during the observation period was paralleled by a corresponding increase in the relative water content during the progression of rejection of the allogeneic grafts. These findings offer indirect support for a link between HA and water accumulation in cardiac graft tissue. The accumulated HA is mainly localized in the swollen interstitial myocardial tissue. Further, the average increase in $\mathrm{HA}$ and the water content in graft tissue corresponds to an HA concentration of $1.6 \mathrm{mg} / \mathrm{ml}$ increased water volume. The microscopic findings suggest that most of the water accumulates in the interstitial tissue, and our calculations indicate that the HA accumulation is sufficient to induce steric exclusion phenomena and thereby an interstitial edema.

We have previously reported that a pronounced accumulation of HA in the smaller airways of patients with acute alveolitis (9) is linked to reduced diffusion capacity, which constitutes an indirect sign of alveolar interstitial edema. In experimental alveolitis the HA accumulation has been localized to the swollen alveolar interstitial tissue space (10). Likewise, the HA content appears to be linked to the water accumulation in the lung tissue during the edematous phase of the lung injury. Thus, the available data indicate that HA accumulation may occur as a general phenomenon in various organs attacked by inflammatory cells and seems to be implicated in the development of tissue edema.

The synthesis of a matrix rich in HA seems to be an important event during the early stages of the formation and remodeling of embryonic tissue. The matrix is thereby stabilized and cell infiltration and migration are stimulated (21-24). Similar effects may be important for tissue reaction during an inflammatory/immunological attack. Thus, the early accumulation of HA and water in the myocardial interstitial tissue during rejection may facilitate the cell infiltration and thereby the rejection. HA may also be an important regulatory molecule for cells involved in the inflammatory process (25-28).

Development of a transplantation edema presents a threat to the function of the cardiac graft due, for example, to an increase in the extracellular pressure and compression of the coronary microvasculature or to an increased diffusion distance for oxygen. Excessive accumulation of HA in the interstitial tissue of rejecting cardiac grafts should influence the water transport in the tissue and may thereby contribute to the development of the transplantation edema. It may therefore be therapeutically advantageous to reduce excessive HA synthesis in cardiac grafts or to enhance the degradation of HA accumulated in the cardiac tissue. To reduce the water-binding capacity of HA and to accelerate its elimination from the rejecting tissue, the HA could be depolymerized by enzymatic treatment. Interestingly, previous investigators have demonstrated that hyaluronidase can reduce ischemic myocardial necrosis $(29,30)$, possibly by reversal of increased coronary vascular resistance and reduction of tissue edema $(31,32)$. 


\section{Acknowledgments}

This work was supported by the Swedish Medical Research Council.

\section{References}

1. Balazs, E. A., T. C. Laurent, and R. W. Jeanloz. 1986. Nomenclature of hyaluronic acid. Biochem J. 235:903.

2. Irwin, T. T. 1981. The healing wound. In Wound Healing: Principles and Practice. T. T. Irwin, editor. Year Book Medical Publishers, Inc., New York. 1-33.

3. Hamerman, D., and D. D. Wood. 1984. Interleukin 1 enhances synovial cell hyaluronate synthesis. Proc. Soc. Exp. Biol. Med. 177:205-210.

4. Yaron, M., I. Yaron, C. Wiletzki, and U. Zor. 1978. Interrelationship between stimulation of prostaglandin $\mathrm{E}$ and hyaluronate production by poly(I)-poly(C) and interferon in synovial fibroblast culture. Arthritis Rheum. 21:694-698.

5. Engström-Laurent, A., N. Feltelius, R. Hällgren, and $\AA$. Wasteson. 1985. Elevated serum hyaluronate in scleroderma: an effect of growth factor induced activation of connective tissue cells? Ann. Rheum. Dis. 44:614-620.

6. Laurent, T. C. 1970. Structure of hyaluronic acid. In Chemistry and Molecular Biology of the Intercellular Matrix. E. A. Balazs, editor. Academic Press, New York. 703-732.

7. Mason, R. M. 1981. Recent advances in the biochemistry of hyaluronic acid in cartilage. Prog. Clin. Biol. Res. 54:87-112.

8. Comper, W. D., and T. C. Laurent. 1978. Physiological function of connective tissue polysaccharides. Physiol. Rev. 58:255-315.

9. Bjermer, L., A. Engström-Laurent, R. Lundgren, L. Rosenhall, and R. Hällgren. 1987. Hyaluronic acid and procollagen III peptide in bronchoalyeolar lavage fluid as indicators of lung disease activity in farmer's lung. Br. Med. J. 295:803-806.

10. Nettelbladt, O., J. Bergh, M. Schenholm, A. Tengblad, and R. Hällgren. 1989. Accumulation of hyaluronic acid in the alveolar interstitial tissue in bleomycin-induced alveolitis. Am. Rev. Respir. Dis. 139:759-762.

11. Jacobsson, J., J. Wahlberg, L. Frödin, B. Odlind, and G. Tufveson. 1989. Organ flush out solutions and cold storage preservation solutions: effect of organ cooling and post ischemic erythrocyte trapping in kidney grafts. An experimental study in the rat. Scand. J. Urol. Nephrol. 23:219-222.

12. Heron, I. 1971. A technique for accessory cervical heart transplantation in rabbits and rats. Acta Pathol. Microbiol. Scand. Sect. A Pathol. 79:366-371.

13. Olausson, M., L. Mjörnstedt, L. Lindholm, and H. Brynger. 1984. Non-suture organ grafting to the neck vessels in rats. Acta Chir. Scand. 150:463-467.
14. Tengblad, A. 1980. Quantitative analysis of hyaluronate in nanogram amounts. Biochem. J. 185:101-105.

15. Hascell, V. C. 1977. Interaction of cartilage proteoglycans with hyaluronic acid. J. Supramol. Struct. 7:101-120.

16. Tengblad, A. 1979. Affinity chromatography on immobilized hyaluronate and its application to the isolation of hyaluronate binding proteins from cartilage. Biochim. Biophys. Acta. 578:281-289.

17. Ripellino, J. A., M. M. Klinger, R. U. Margolis, and R. K. Margolis. 1985. The hyaluronic acid binding region as a specific probe for the localization of hyaluronic acid in tissue sections. J. Histochem. Cytochem. 33:1060-1066.

18. Eriksson, S., J. R. E. Fraser, T. C. Laurent, H. Pertoft, and B. Smedsred. 1983. Endothelial cells are a site of uptake and degradation of hyaluronic acid in the liver. Exp. Cell Res. 144:223-228.

19. Johnsson, R. L., and M. Ziff. 1976. Lymphokine stimulation of collagen accumulation. J. Clin. Invest. 58:240-248.

20. Wahl, S. M., and J. B. McCarthy. 1978. Lymphocyte-mediated activation of fibroblast proliferation and collagen production. J. Immunol. 121:942-946.

21. Toole, B. P. 1981. Glycosaminoglycans in morphogenesis. In Cellular Biology of Extracellular Matrix. E. D. Hay, editor. Plenum Publishing Corp., New York. 251-294.

22. Le Dourain, N. M. 1984. Cell migrations in embryos. Cell. 38:353-360.

23. Tucker, R. P., and C. A. Erickson. 1984. Morphology and behaviour of quail neural crest cells in artificial three-dimensional extra-cellular matrices. Dev. Biol. 104:390-405.

24. Stern, C. D. 1984. Mini-review: hyaluronidases in early embryonic development. Cell Biol. Int. Rep. 8:703-717.

25. Håkansson, L., R. Hällgren, and P. Venge. 1980. Regulation of granulocyte function by hyaluronic acid. J. Clin. Invest. 66:298-305.

26. Forester, J. V., and E. A. Balazs. 1980. Inhibition of phagocytosis by high molecular weight hyaluronate. Immunology. 40:435-436.

27. Ahlgren, T., and C. Jarstrand. 1984. Hyaluronic acid enhances phagocytosis of human monocytes in vitro. J. Clin. Immunol. 4:246249.

28. Shannon, B. T., and S. H. Love. 1980. Participation of hyaluronic acid in the macrophage disappearance reaction. Immunol. Commun. 9:357-370.

29. MacLean, D, M. C. Fischbein, P. R. Maroko, and E. Braunwald. 1976. Hyaluronidase-induced reductions in myocardial infarct size. Science (Wash. DC). 194:199-200.

30. Maroko, P. R., P. Libby, C. H. Bloor, B. E. Sobel, and E. Braunwald. 1972. Reduction by hyaluronidase of myocardial necrosis following coronary artery occlusion. Circulation. 46:430-477.

31. Sunnergren, K. P., and M. J. Rovetto. 1983. Hyaluronidase reversal of increased coronary vascular resistance in ischemic rat heats. Am. J. Physiol. 245:H183-H188.

32. de Olivera, J. R., and M. N. Levy. 1960. Effect of hyaluronidase upon the water content of the ischemic myocardium. Am. Heart J. 60:106-109. 